\title{
Extraction of uranium from nuclear industrial effluent using polyacrylhydroxamic acid sorbent
}

\author{
S. K. Satpati · S. Pal · D. Goswami • \\ P. K. Tewari $\cdot$ S. B. Roy
}

Received: 10 October 2012/Revised: 20 June 2013/Accepted: 9 October 2013/Published online: 23 October 2013

(C) Islamic Azad University (IAU) 2013

\begin{abstract}
Solid-phase extraction process using chelating sorbent is a novel technique due to its high separation efficiency and simplicity. A designed three-dimensional crosslinked hydrophilic chelating polymeric sorbent, polyacrylhydroxamic acid, was developed for enhanced uptake of uranium from waste solution ( $\mathrm{pH}$ 6-9) by complexation between the sorbent's active functional group and uranium. The sorbent was synthesized by polymerization of acrylamide with cross-linking agent, followed by conversion and functionalization with hydroxylamine hydrochloride. In this paper, removal and recovery of uranium from effluent of uranium material processing plant in the presence of competitive ions such as sodium, calcium and magnesium were studied using the sorbent. Uranium uptake property of the developed sorbent was also investigated with respect to sorbent's physical characteristics such as bead size distribution and bead swelling, in batch experiments. Distribution coefficient of uranium in the sorbent was substantially high (1,250 $\mathrm{mL}$ of effluent/g of sorbent), and immobilization factor was 0.028 . The results showed that more than $90 \%$ recovery of uranium is viable from nuclear effluent without preconditioning. Breakthrough profiles of column operation were successfully described for effective removal of uranium in continuous mode. The novel sorbent has been used for polishing the nuclear wastewater and hence to mitigate the environmental issues.
\end{abstract}

Keywords Competitive ions $\cdot$ In-house sorbent $\cdot$ Physical characteristics · Uranium recovery

S. K. Satpati $(\bowtie) \cdot$ S. B. Roy

Uranium Extraction Division (UED), Bhabha Atomic Research

Centre (BARC), Trombay, Mumbai 400085, India

e-mail: santoshkumarsatpati@gmail.com

S. Pal · D. Goswami · P. K. Tewari

Desalination Division (DD), Bhabha Atomic Research Centre

(BARC), Trombay, Mumbai 400085, India

\section{Introduction}

The separation of uranium from contaminated water has become an environmental issue, which needs to be addressed. Recently, separation of uranium from diluted aqueous solution has been playing important role in separation sciences and has been engaging more attention than before (De 2000; Gupta and Singh 2003) with regard to environmental impact. Release of uranium-bearing aqueous solution from uranium material processing plant is found to be one of the major sources of environmental contaminants with the radioactive material, which is required to be separated to avoid a detrimental effect to aquatic life as well as human beings (Liao et al. 2004; Van Horn and Huang 2006; Li et al. 2010; Zhang et al. 2011).

Uranium (in ppm level) and other metals (in percentage level) are present in effluents of uranium material processing facilities. Several works have been carried out on suitable material development as well as techniques to remove and recover uranium from these diluted aqueous solutions (below $10 \mathrm{ppm}$ ) adopting different processes such as ion exchange, solvent extraction, biosorption/ remediation, chromatographic, electrodeposition, membrane separation (Tsuruta 2002; Lee et al. 2002; 2004; Kulkarni 2003; Chaudhury et al. 2003; Mohite et al. 2003; Dabrowski et al. 2004; Lloyd et al. 2005; Amamoto et al. 2005; Mirjalili and Roshani 2007; James et al. 2009; Akhtar et al. 2009; Singh et al. 2009). Among all, solidphase extraction process using uranium-specific chelating sorbent has gained popularity due to its high separation efficiency even in ppb level, with adequate reproducibility of retention and simplicity (Huikuri and Salonen 2000; Chellam and Clifford 2002; Matsumiya et al. 2003; Starvin and Rao 2004; Banerjee et al. 2004; Gu et al. 2005; Aydin and Soylak 2007; Atia et al. 2007; Ciftci 2010). Various 
polymeric sorbents have been designed, developed and tested for recovery of uranium from diluted aqueous medium and nuclear effluents (Akkas and Guven 2000; Li et al. 2007; Mangrulkar et al. 2008; Sprynskyy et al. 2010; Sepehrian et al. 2012) and also from sea water (Rivas et al. 2001; Kavash et al. 2004). Scientific approaches ensuring efficiency and selectivity of sorbents based on the formation of functional groups impregnated on polymeric material are required for optimal filling of the metal coordination sphere (Lin et al. 2010; Hosseini and Hosseini-Bandegharaei 2011; Hang Wang et al. 2012). Thorough and careful screening of the polymers for specific use is required for choosing a sorbent for separation of uranium from normal composition and nature of its waste solutions such as $\mathrm{pH}$, presence of other competitive elements, and temperature (Nascimentoa et al. 2004; Ladeira and Morais 2005). Selection of low cost but effective sorbent was needed to explore for economical viability of the industrial process. The major problems pertaining to the development of a suitable separation technique for uranium from nuclear waste solution are due to its very low concentration (below $10 \mathrm{ppm}$ ) and chemical form in solution (mostly $\mathrm{UO}_{2}^{2+}$ ) and also due to presence of higher concentration of competitive ions in the solution. Nitrogen and oxygen containing donor functional groups based cross-linked polymers are identified as the most promising candidate among sorbents. Few sorbents such as calixarenes, crown ethers, amidoximebased resins and sorbents (Kawai et al. 2000; Choi and Nho 2000; Zhang et al. 2003; Sodaye et al. 2008) were found to be highly selective towards uranium separation, but they are quite expensive, having low sorption kinetics, and preparation of the sorbents requires instruments such as electron beam radiation grafting, as well as base monomer, i.e. acrylonitrile which is toxic in nature. Therefore, to develop low-cost selective sorbent with adequate sorption kinetics for uranium separation and recovery aiming ecofriendly process from uranium-bearing nuclear liquid wastes was a challenging task. Poly[acrylhydroxamic acid], viz. PHOA, (Pal et al. 2006; Pal and Tewari 2010) sorbent was found to be useful for selective removal of uranium from contaminated water in their normal condition.

The research presented here focuses on utility of PHOA sorbent with respect to its physical characteristics and uranium separation behaviour. The studies were carried out targeting recovery of uranium from its waste solution in the presence of other competitive metal ions such as magnesium and calcium. Column experiment was conducted for evaluating the removal and recovery efficiency of uranium in a continuous mode. This research was carried out in 2012 for uranium removal and recovery using in-house developed sorbent for Uranium Metal Plant (UMP) at Bhabha Atomic Research Centre (BARC), India.

\section{Materials and methods}

Reagents

Acrylamide, hydroxylamine hydrochloride, methanol, acetone, sodium hydroxide, $\mathrm{NaCl}, \mathrm{MgCl}_{2}, \mathrm{CaCl}_{2}$, procured locally, and $N, N$-methylene-bis-acrylamide (E. Merck) were used as received without purification. All reagents were of analytical grade.

Sorbent preparation

Preparation of sorbent consists of two steps, preparation of polyacrylamide (PAAm) from monomer acrylamide (AAm) and conversion of PAAm to polyacrylhydroxamic acid (PHOA). Cross-linked polyacrylamides were prepared by polymerizing an aqueous solution of acrylamide and $\mathrm{N}, \mathrm{N}$ methylene-bis-acrylamide in a mole ratio $0.95 / 0.05$ (required degree of cross-linking) with a fixed number of initiator at $60{ }^{\circ} \mathrm{C}$. After achieving room temperature, acetone was poured in the gel mass of polyacrylamide for phase inversion. After about $24 \mathrm{~h}$, the gel was crumpled and washed with distilled water. For conversion to PHOA, a solution of hydroxyl amine hydrochloride and sodium hydroxide was added to cross-linked polyacrylamide and the reaction was continued for $6 \mathrm{~h}$ at $70{ }^{\circ} \mathrm{C}$. The resultant polymeric sorbent was cooled to room temperature, filtered and washed with distilled water thoroughly. The sorbent was dried in an oven at $120{ }^{\circ} \mathrm{C}$ for $5 \mathrm{~h}$. Prepared PHOA sorbent was peach-coloured irregular solid beads.

\section{Experimental procedure}

Dried sorbent beads were crushed and then sieved using different ASTM steel wire meshes. The sorbent remained in each mesh container was collected and labelled for respective mesh size beads. The sorbent as prepared was taken for four size distribution measurements, namely 10, 16, 18 and 30 meshes. Distribution pattern is shown in Fig. 1. Individual mesh size sorbent bead was used for swelling tests and tests for uranium uptake varying sorbent mesh size. In the study, intention was to evaluate the performance of mixed sorbent, as prepared and shown in Fig. 1. Batch and column operations were carried out in laboratory scale at room temperature (RT) $28{ }^{\circ} \mathrm{C}$. For swelling tests, salt solutions were prepared by adding known quantity of chemical in laboratory-prepared distilled water (DW). The characteristic of effluent generated in uranium refining plant is shown in Table 1, with range of conditions. A typical plant effluent having $9.81 \mathrm{mg} \mathrm{U} / \mathrm{L}, 576 \mathrm{mg} \mathrm{Ca} / \mathrm{L}, 15,121 \mathrm{mg} \mathrm{Mg} / \mathrm{L}$, $74,211 \mathrm{mg} \mathrm{NO}_{3} / \mathrm{L}$ at $\mathrm{pH} 8.1$ was used to carry out all experiments except swelling tests. The as-prepared sorbent and effluent were used for experiments of uranium uptake, kinetic evaluation and column performance. 


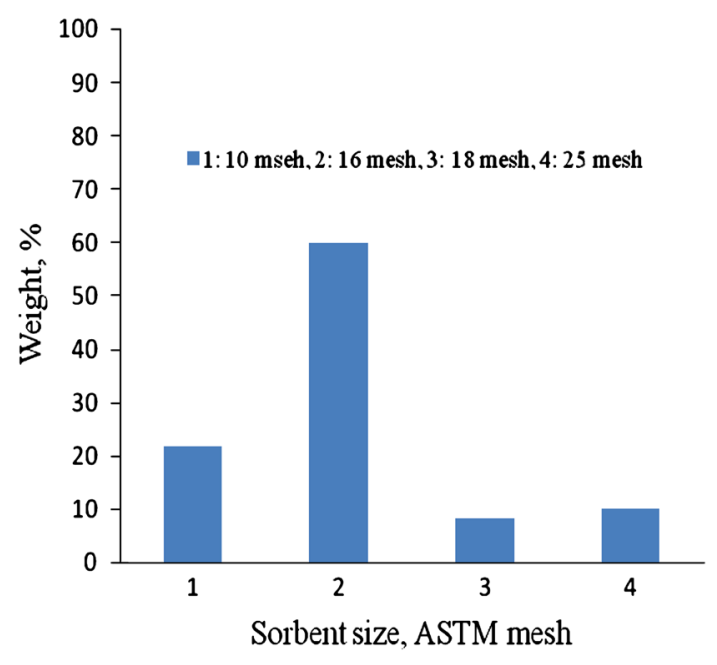

Fig. 1 Mesh size distribution of sorbent

Table 1 Composition of plant effluent

\begin{tabular}{llll}
\hline Element & Concentration $(\mathrm{mg} / \mathrm{L})$ & Element & Concentration $(\mathrm{mg} / \mathrm{L})$ \\
\hline $\mathrm{Al}$ & $<5.0$ & $\mathrm{Ca}$ & $500-800$ \\
$\mathrm{Cr}$ & $<5.0$ & $\mathrm{Mg}$ & $15,000-17,000$ \\
$\mathrm{Fe}$ & $<5.0$ & $\mathrm{Mn}$ & $<1.0$ \\
$\mathrm{Cu}$ & $<5.0$ & $\mathrm{Ni}$ & $<1.0$ \\
$\mathrm{Cd}$ & $<5.0$ & $\mathrm{U}$ & $\sim 10$ \\
$\mathrm{pH}=7.5-8.5$ & & \\
Nitrate $=70,000-80,000 \mathrm{mg} / \mathrm{L}$ & & \\
\hline
\end{tabular}

Swelling tests

All swelling tests were carried out in a $250-\mathrm{mL}$ measuring cylinder having bottom drain-out facility for medium removal. One gram dry sorbent and $100 \mathrm{~mL}$ swelling medium were used for the swelling tests. Swelling medium was poured in the cylinder having measured quantity dried sorbent. Swelling time and medium draining time were 3 and $1 \mathrm{~h}$, respectively, for all the tests. Volume of swelled sorbent (after draining) was evaluated directly from the measuring cylinder. One gram dry sorbent was poured in 10-mL measuring cylinder, and tap volume of compacted bead was evaluated as dry sorbent volume. Five different swelling mediums, distilled water, effluent and solutions of $\mathrm{NaCl}, \mathrm{CaCl}_{2}$ and $\mathrm{MgCl}_{2}$, were used for the study. $\mathrm{Na}^{+}$ion in low concentration is normally present in wastewater. $\mathrm{Ca}^{2+}$ and $\mathrm{Mg}^{2+}$ ions in high concentration were present in the effluent (Table 1). Different cation concentrations (monovalent and di-valent), for $\mathrm{Na}^{+}: 10-7,012 \mathrm{mg} / \mathrm{L}$, for $\mathrm{Mg}^{++}: 27-10,021 \mathrm{mg} / \mathrm{L}$ and for $\mathrm{Ca}^{++}: 23-812 \mathrm{mg} / \mathrm{L}$, were used for evaluating effect of metal ion and its concentration on sorbent swelling. Solution $\mathrm{pH}$ was maintained at about 8 by adding $0.01(\mathrm{M})$ ammonium hydroxide solution as and when required, just before use.
Sorption study

Uranium uptake of the resin was evaluated by equilibrating a known quantity of dry sorbent in contact with the effluent. For uptake study, $100 \mathrm{~mL}$ effluent was contacted with $0.5 \mathrm{~g}$ dry sorbent of different mesh size 10,16,18 and 25 as well as mixed (distributed mesh) separately for $24 \mathrm{~h}$. Next day, the resultant solutions were filtered using $1-\mu \mathrm{m}$ filter cloth and filtrates were analysed for uranium ion. Only filtrate of mixed-sorbent-treated solution was taken for analysis of $\mathrm{Ca}$ and $\mathrm{Mg}$ ions for comparing sorption characteristics with that of uranium. For sorption kinetic test, $1 \mathrm{~g}$ mixed sorbent was contacted with $200 \mathrm{~mL}$ effluent in different time intervals $22,26,28,45,60,75,90,105,120,135,150,165,180,195$, 210, 225, 240, $270 \mathrm{~min}$ and $5 \mathrm{~mL}$ of each sample was collected in the time intervals from contacting medium using measuring pipette and the samples were analysed for uranium concentration. Volume reduction after each sampling was incorporated in resultant's uranium concentration calculation.

The uptake of metal ions by the sorbent was calculated according to the mass balance of the metal ions as expressed $q=\left[\left(C_{0}-C_{\mathrm{e}}\right) V\right] / M$

and the sorption equilibrium expressed by the distribution coefficient, $K_{d}(\mathrm{ml} / \mathrm{g})$ as

$K_{d}=q / C_{\mathrm{e}}$

where $q$ is the amount of metal ions sorbed onto the dry sorbent $(\mu \mathrm{g} / \mathrm{g}), C_{0}$ is the concentration of metal ions in the initial solution $(\mu \mathrm{g} / \mathrm{mL}), C_{\mathrm{e}}$ is the concentration of metal ions in aqueous phase at equilibrium $(\mu \mathrm{g} / \mathrm{mL}), V$ is the volume of the aqueous phase $(\mathrm{mL})$, and $M$ is the mass of the dry sorbent used $(\mathrm{g})$

$$
\text { Sorption in } \%=100 \times(\text { Amount of uranium sorbed }) /
$$

(Amount of uranium present in effluent)

For continuous sorption column mode experiment, a glass column of size $24.4 \mathrm{~mm}$ id and height $760 \mathrm{~mm}$ was loaded with $5 \mathrm{~g}$ mixed sorbent. The effluent was passed through the column at flow rate $2 \mathrm{~mL} / \mathrm{min}$ at room temperature. Outlet solution of the column was collected at 10, 40, 70, 100, 130, $160,190,220,250,260,300,330,350,370$ min time interval after starting the flow, and collected samples were analysed for average uranium content.

\section{Elution study}

The loaded sorbents (mixed) were used for elution performance evaluation. The metal ion loaded with mixed sorbent $(0.5 \mathrm{~g})$ was treated with $100 \mathrm{~mL} 0.5 \mathrm{M} \mathrm{HCl}$, elution medium at room temperature for $24 \mathrm{~h}$. Next day, the elute sample was collected for metal ion analysis. The $1 \mathrm{~g}$ loaded sorbent 
(sorption kinetic) was employed with $200 \mathrm{~mL} 0.5 \mathrm{M} \mathrm{HCl}$ for evaluating elution kinetics. Five millilitres of sample elute solution was collected in each time interval of $12,14,15,30$, $45,60,75,90,105,120,150,180,195,210,225,240$, 270 min after starting $\mathrm{HCl}$ flow, and the eluted solution samples were analysed for uranium content. Volume reduction after each sampling was accounted for uranium concentration calculation in eluted solutions.

$$
\begin{aligned}
\text { Elution in } \%= & 100 \times(\text { Amount of uranium eluted }) \\
& /(\text { Amount of uranium sorbed by the sorbent }) \\
& \text { and immobilization factor } \\
& =(1-\text { Elution factor }) .
\end{aligned}
$$

The same glass column was used with $5 \mathrm{~g}$ loaded mixed sorbent (column sorption) for continuous elution column mode experiment. $0.5 \mathrm{M} \mathrm{HCl}$ was passed through the column at flow rate $2 \mathrm{~mL} / \mathrm{min}$ at room temperature, outlet solution of the column was collected at 10, 40, 70, 100, $130,160,190,220,250,280,310,340,370$ min interval after starting the flow, and the collected samples were analysed for average uranium content.

\section{Sample and analysis}

Plant effluent was filtered through 1- $\mu$ m filter cloth, and filtrate is taken for the experiments. Estimation of magnesium, calcium and uranium in the effluent sample (before the sorption experiment), the sorption filtrate and eluted medium was carried out using inductively coupled plasmaatomic emission spectrometer (ICP-AES) instrument with respect to standard solutions. All the experiments were performed in duplicates, and total relative standard deviation (RSD) was evaluated as $\pm 5 \%$.

\section{Results and discussion}

The used sorbent was newly developed and in-house-prepared cross-linked cation exchange resin. The sorbent's characterization and performance evaluation study using effluent of uranium refining plant was carried first time, and the same has been reported in the paper. The effluent contains different cationic elements of higher concentration along with uranium of concentration $<10 \mathrm{ppm}$. The composition of the effluent is in Table 1. The most challenging task was to treat such high concentration nitrate solution $(>7,000$ times compared to uranium) having alkaline $\mathrm{pH}$, which affects the properties of organic material/ion exchange resin and deteriorates the functionality of chelating groups. Selective removal of uranium from a lean stream having oxidizing and alkaline medium was main requirement for polishing the effluent before disposal to environment. Sorbent usefulness also depends on the probability of valuable recovery from the laden sorbent matrix and reusability of the sorbent thereafter. Sorbent characterization data in terms of elemental composition and ion exchange capability were reported elsewhere (Pal et al. 2006). Besides selectivity of the sorbent in such effluents with high dissolved solids content, total uptake and kinetics also play important role in performance evaluation of the sorbent.

\section{FTIR spectra}

FTIR spectra of virgin PHOA sorbent and PHOA loaded with uranium were taken using $\mathrm{KBr}$ pelletization technique. $\mathrm{N}-\mathrm{O}$ peak spectra of virgin and loaded PHOA were compared for understanding the interaction of uranium with the sorbent. The IR spectra recorded for (A) virgin PHOA, (B) uranium-loaded PHOA and (C) eluted PHOA samples are shown in Fig. 2. Shift of characteristic sorption peaks for carbonyl stretching from 1,689 to $1,640 \mathrm{~cm}^{-1}$ and for $\mathrm{N}-\mathrm{O}$ stretching from 1,321 to $1,384 \mathrm{~cm}^{-1}$ has indicated a strong interaction of hydroxamates with uranium. Uptake of uranium in the sorbent was attributed to additional peaks at $934,1,098 \mathrm{~cm}^{-1}$ in loaded sorbent spectra (B), which are characteristics of O-U-O stretching vibrations and $\mathrm{N}-\mathrm{H}$ bending vibrations, respectively. Uranium elution and sorbent reusability were indicated comparing spectra (A) and (C), which are similar in nature, and peak for $\mathrm{O}-\mathrm{U}-\mathrm{O}$ stretching vibration was absent.

\section{Effect of mesh size on swelling}

Swelling effect of the sorbent in distilled water with the mesh size variation is shown in Fig. 3. Swell volume increased with the increase in mesh size due to increase in total surface area. Sorbent's surface pores were getting opened up in the water because of hydrophilic nature of the sorbent, as designed for the purpose. Sorption characteristic varies proportionately with sorbent's swelled volume. Increase in swell volume between 15 and 20 mesh sizes was sharp from 33 to $36 \mathrm{~mL}$, and thereafter, volume gradient reduces, $37 \mathrm{~mL}$ for 25 mesh size, as volume effect was dominated by interbead voids. The result was confirmed by measuring volume of dry sorbent, which is shown in Fig. 3, secondary $y$-axis. Bulk density of dry sorbent increased with the decrease in dry sorbent bead size.

\section{Effect of competitive ions on sorbent swelling}

Variation in swelling volume of the sorbent was evaluated in variable concentration of different metal ions such as $\mathrm{Na}^{+}$, $\mathrm{Ca}^{++}$and $\mathrm{Mg}^{++}$present in the feed solutions. The effect of $\mathrm{Na}^{+}$ion concentration on different mesh size sorbents is shown in Fig. 4. Swelled sorbent volume decreased rapidly for all the sizes and was stabilized around at 7,000 mg/ $\mathrm{L} \mathrm{Na}^{+}$ 

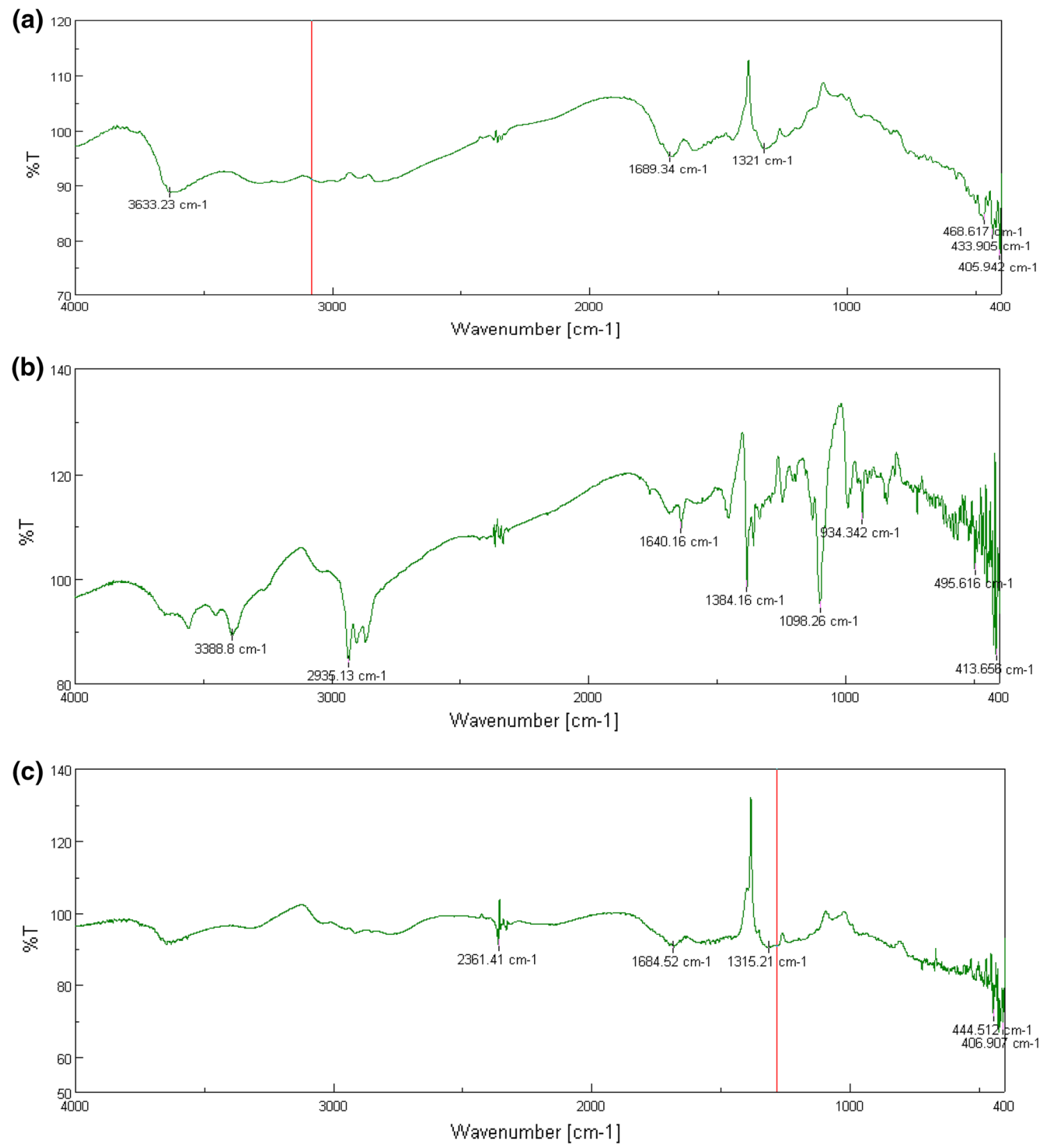

Fig. 2 FTIR spectra of a PHOA, b loaded PHOA and c eluted PHOA

ion concentration. At lower ion concentration of sodium ion ( $\sim 10 \mathrm{mg} / \mathrm{L}$ ), swelled sorbent volume was about $32-34 \mathrm{~mL}$ range and it was reduced to about $14-16 \mathrm{~mL}$ range at higher concentration $(\geq 7,000 \mathrm{mg} / \mathrm{L})$. Monovalent ion was used to analyse and compare the effect with the result of the divalent cations. Uranium processing plant effluents are treated and neutralized with magnesium oxide before regulated disposal. Calcium and magnesium ions in higher concentration were present in the effluent. Effects of different concentrations of $\mathrm{Ca}^{++}$ion and $\mathrm{Mg}^{++}$ion on sorbent swelling are shown in Figs. 5 and 4, respectively. Swelling volume decreased sharply with concentration of both the ions. The presence of calcium ion was found to be more detrimental as swelling volume decreases to around $7-9 \mathrm{~mL} / \mathrm{g}$ sorbent for $\mathrm{Ca}^{++}$ concentration about $500 \mathrm{mg} / \mathrm{L}$, whereas similar effect was observed for $\mathrm{Mg}^{++}$concentration at about $1,000 \mathrm{mg} / \mathrm{L}$. Thereafter, further reduction in the volume was not noticed. Though swelled volume decreased for all the cases, due to relative valency difference and atomic size variation, the negative slope rate was sharper for divalent ions compared to monovalent ions. Comparing the figures, it was noticed that sorbent swelled volume was $12-16 \mathrm{~mL} / \mathrm{g}$ for divalent ion concentration $20-30 \mathrm{mg} / \mathrm{L}$, which was equivalent to the monovalent ion concentration $>10,000 \mathrm{mg} / \mathrm{L}$. 


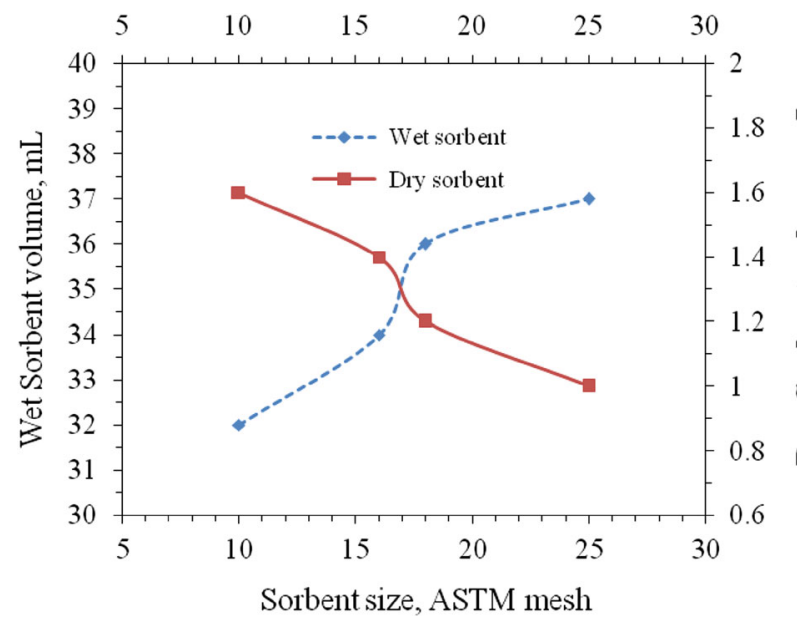

Fig. 3 Volume of sorbent in dry and fully swelled in DW

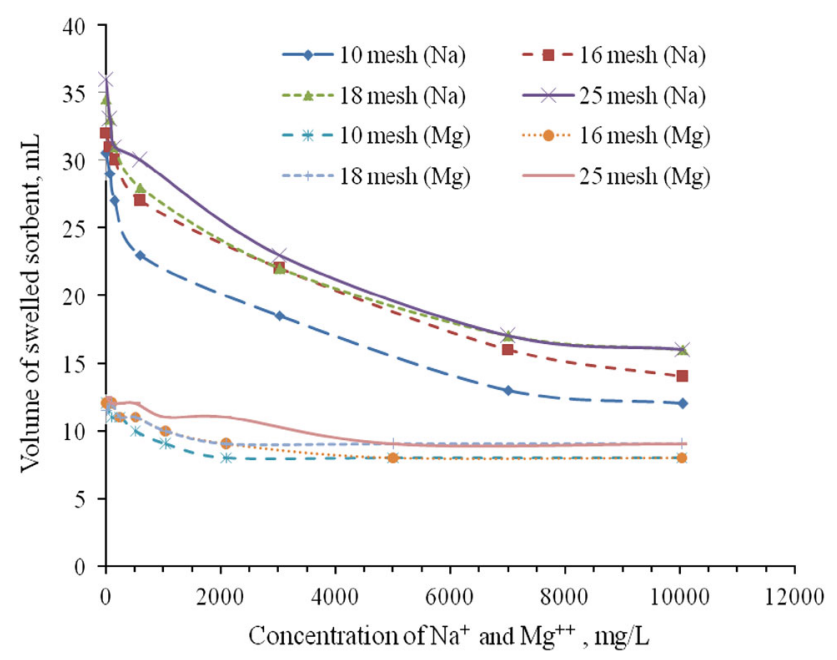

Fig. 4 Effect of $\mathrm{Na}^{+}$and $\mathrm{Mg}^{++}$concentrations on swelling of sorbent

Sorption characteristics and effect of mesh size

Separation and recovery characteristics of the sorbent for uranium, magnesium and calcium using plant effluent (batch experiment) are listed in Table 2. Bead size distribution for mixed sorbent is shown in Fig. 1. Weight percentage of up to 18 mesh size bead was predominant, about $90 \%$. Distribution coefficient $(\mathrm{Kd})$ of uranium was substantially higher, about 100 times than that of calcium and magnesium. Per cent sorption of uranium was about $93 \%$, whereas for calcium and magnesium, it was about 10 and $15 \%$, respectively. The sorbent is found to be highly selective to uranium. Along with uranium, other metal ions were got stripped out from the sorbent and the sorbent was almost fresh (Fig. 1c). Recovery of uranium and magnesium was about $97 \%$ and that of calcium was more than $85 \%$. Hence, the sorbent is suitable for repeated use, which is one of the criteria for economical application of the sorbent.

Uranium uptake profile varying sorbent mesh size is shown in Fig. 6. Uranium uptake increased sharply up to 18

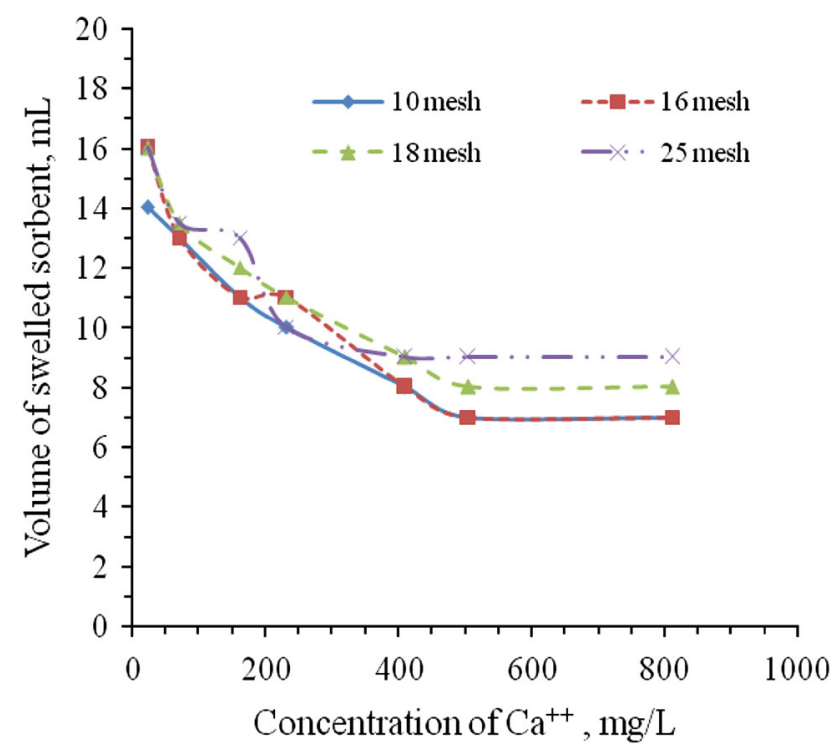

Fig. 5 Effect of $\mathrm{Ca}^{++}$concentration on swelling of sorbent

Table 2 Sorption characteristics of uranium, magnesium and calcium using plant effluent in batch experiment

\begin{tabular}{llll}
\hline $\begin{array}{l}\text { Parameters studied } \\
\text { (element) }\end{array}$ & \multicolumn{3}{l}{ Uranium processing plant effluent } \\
\cline { 2 - 4 } & $(\mathrm{U})$ & $(\mathrm{Mg})$ & $(\mathrm{Ca})$ \\
\hline Sorption \% $(24 \mathrm{~h})$ & $92.59 \pm 1.8$ & $9.67 \pm 0.2$ & $14.92 \pm 0.3$ \\
$K_{d}=\left(C_{0}-C_{\mathrm{e}}\right) / C_{\mathrm{e}}$. & $1,250 \pm 14.5$ & $10.71 \pm 0.3$ & $17.64 \pm 0.4$ \\
$\mathrm{~V} / \mathrm{m}(\mathrm{mL}$ of effluent/g & & & \\
$\quad$ of dry sorbent $)$ & & & \\
$\begin{array}{l}\text { Elution \% (24 h) } \\
\text { Immobilization factor }\end{array}$ & 0.028 & 0.035 & 0.145 \\
\hline
\end{tabular}

mesh size as swelling volume increased (Fig. 3), and thereafter, the increase was not prominent. Maximum uptake of $1,142,1,247$ and $1,252 \mu \mathrm{g} \mathrm{U} / \mathrm{g}$ sorbent was observed with 16 , 18 and 25 mesh size beads, respectively. Effective uptake was reduced with the increase in mesh size because of hindrance of sorbent swelling due to compactness of lower size beads (density increased).

\section{Kinetics with plant effluent using mixed PHOA}

Sorption and elution kinetics of PHOA sorbent with respect to uranium uptake using the plant effluent in batch experiments are shown in Fig. 7. Within 4 h, $91 \%$ uranium separation from the effluent was observed. The uptake was further enhanced to about $93 \%$ by increasing sorption time to $24 \mathrm{~h}$. Faster kinetics were observed during initial $30 \mathrm{~min}$ as more sorption sites were available to the metallic ions. The sorbent was found to be useful for separation of uranium from the effluent and polishing the same before disposal. A substantial amount, about $75 \%$ of uranium elution within 10 min and $97.5 \%$ elution, was observed in $3 \mathrm{~h}$ with the $0.5 \mathrm{M}$ 


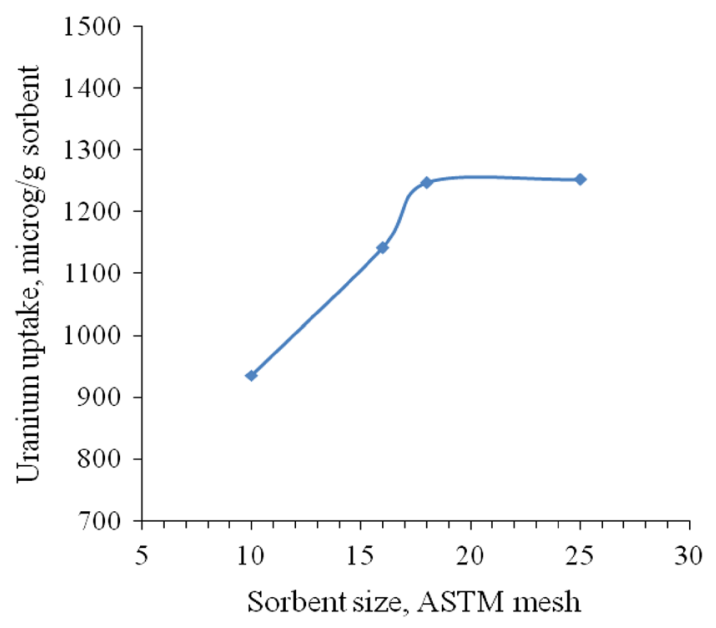

Fig. 6 Uranium uptake with mesh size variation (effluent)

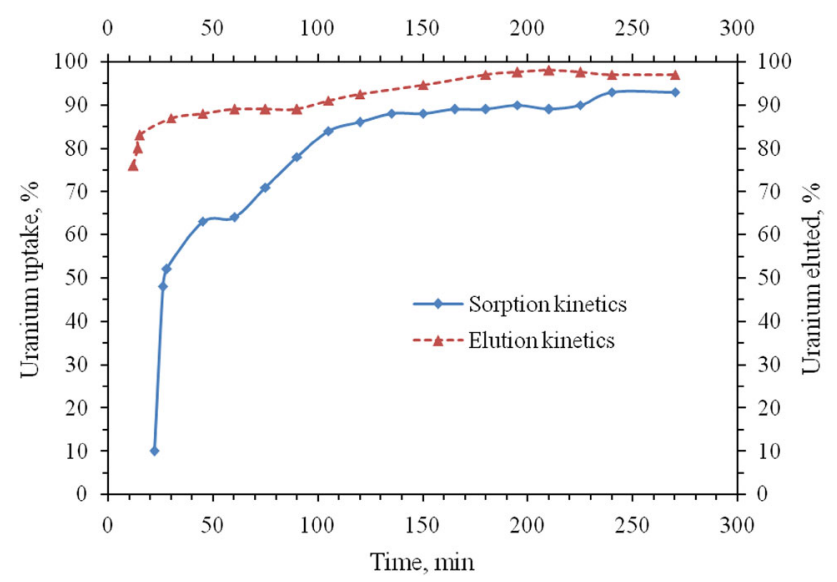

Fig. 7 Uranium sorption and elution performance with time (effluent)

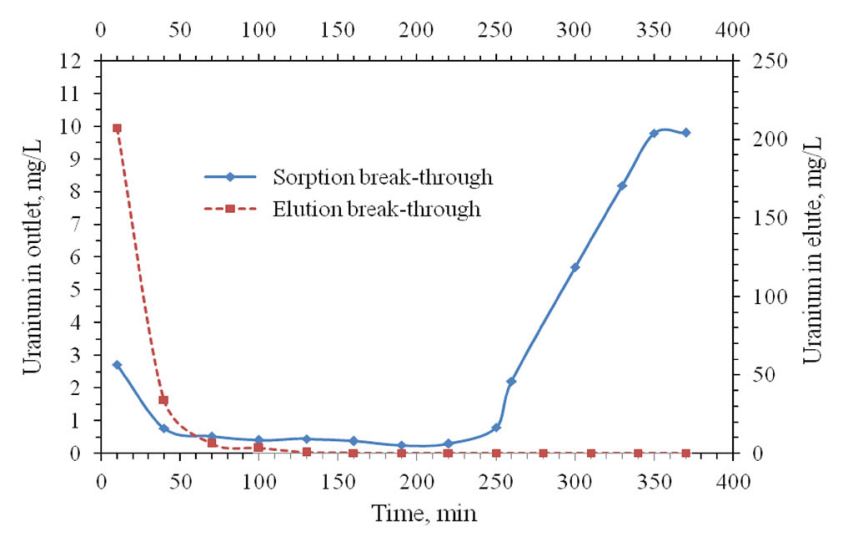

Fig. 8 Sorption and elution breakthrough in column (effluent)

$\mathrm{HCl}$ eluent. The elution kinetics were found to be faster than the sorption kinetics. There was about $2 \%$ weight loss of the sorbent in the laboratory-scale batch experiment. Degradation of the sorbent is envisaged to be appeared in sorbent reuse due to the presence of high concentration of nitrate in the effluent (oxidizing medium) and also because of sorbent attrition.
Removal and recovery of uranium in column operation

Breakthrough results for sorption profile as well as elution profile in column experiments are shown in Fig. 8. In the column sorption operation, initial concentration of $2.6 \mathrm{mg} /$ $\mathrm{L}$ uranium was noticed in first $10 \mathrm{~min}$ which may be due to channelling of flow and outlet concentration came down to below $0.7 \mathrm{ppm}$ within next $30 \mathrm{~min}$. About $10 \%$ sorption breakthrough was achieved within $250 \mathrm{~min}$, and bed was used up within $1 \mathrm{~h}$ in the elution breakthrough because of faster kinetics of elution process.

\section{Conclusion}

The cross-linked polymer sorbent, PHOA, which was an inhouse-prepared sorbent in the facility, was used for the removal of uranium from uranium refining plant effluent. It was rare in kind for uranium recovery from wastewater in alkaline medium with high sorption characteristics. Selective uptake of uranium $93 \%$ from the effluent was obtained due to its effective hydrophilic nature and availability of strong chelating functional groups in the polymer structure. Ecofriendly synthesis route of the sorbent was an added advantage towards safe industrial waste disposal. The nuclear fuel, uranium, was recovered eluting the sorbent with appreciable performance efficiency, with $97.5 \%$ elution in $0.5 \mathrm{M} \mathrm{HCl}$ acid medium. The solid-state extraction process for removal/ decontamination as well as recovery of radionuclides is not only a remedial method for environment protection, but it also implies a new horizon as another member in a closed-loop technique. Batch-mode laboratory-scale test results encouraged conducting column study for establishing the continuous mode of sorption $(<0.5 \mathrm{mg} / \mathrm{L}$ uranium in outlet $)$ and recovery and also for further scale up of the process.

Acknowledgments Help received from Shri Chunu Soren from MTS/DD/BARC and Shri Amit Sharma UED/BARC is acknowledged.

\section{References}

Akhtar K, Khalid AM, Akhtar MW, Ghauri MA (2009) Removal and recovery of uranium from aqueous solutions by $\mathrm{Ca}$-alginate immobilized Trichoderma harzianum. Bioresour Technol 100:4551-4558

Akkas P, Guven O (2000) Enhancement of uranyl ion uptake by prestructuring of acrylamide-maleic acid hydrogels. J Appl Polym Sci 78:284-289

Amamoto I, Terai T, Oobayashi H, Fujit R (2005) Separation and recovery study of uranium from spent $\mathrm{NaF}$ (filters). J Phys Chem Solids 66:602-607

Atia AA, Donia AM, El-Enein SA, Yousif AM (2007) Effect of chain length of aliphatic amines immobilized on a magnetic glycidyl methacrylate resin towards the uptake behaviour of $\mathrm{Hg}$ (II) from aqueous solutions. Sep Sci Technol 42(2):403-420

Aydin FA, Soylak M (2007) Solid phase extraction and preconcentration of uranium (VI) and thorium (IV) on dilute XAD761 prior 
to their inductively coupled plasma mass spectrometric determination. Talanta 72(1):187-192

Banerjee D, Mondal BC, Das AKJ (2004) Synthesis and analytical application of a new chelating resin containing 8-aminoquinoline group. J Ind Chem Soc 81(1):50-53

Chaudhury S, Singh Mudher KD, Venugopal V (2003) Recovery of uranium from fluoride matrix by solid state reaction routes. J Nucl Mater 322:119-125

Chellam S, Clifford DA (2002) Physical-chemical treatment of groundwater contaminated by leachate from surface disposal of uranium tailings. J Environ Eng 128:942-952

Choi SH, Nho YC (2000) Adsorption of $\mathrm{UO}_{2}^{2+}$ by polyethylene adsorbents with amidoxime, carboxyl, and amidoxime/carboxyl group. Radiat Phys Chem 57:187-193

Ciftci H (2010) Separation and solid phase extraction method for the determination of cadmium in environmental samples. Desalination 263:18-22

Dabrowski A, Hubicki Z, Padkościelny P, Robens E (2004) Selective removal of the heavy metal ions from waters and industrial wastewater by ion-exchange method. Chemosphere 56(2):91-106

De AK (2000) Environmental chemistry, 4th edn. New Age International Publishers, New Delhi

$\mathrm{Gu} \mathrm{B}, \mathrm{Ku}$ Y, Brown GM (2005) Sorption and desorption of perchlorate and U(VI) by strong-base anion-exchange resins. Environ Sci Technol 39(3):901-907

Gupta CK, Singh H (2003) Uranium resource processing: secondary resources. Springer, Germany

Hosseini MS, Hosseini-Bandegharaei A (2011) Comparison of sorption behaviour of Th(IV) and U(VI) on modified impregnated resin containing quinizarin with that conventional prepared impregnated resin. J Hazard Mater 190:755-765

Huikuri P, Salonen L (2000) Removal of uranium from Finnish groundwaters in domestic use with a strong base anion resin. J Radioanal Nucl Chem 245:385-393

James D, Venkateswaran G, Prasad Rao T (2009) Removal of uranium from mining industry feed simulant solutions using trapped amidoxime functionality within a mesoporous imprinted polymer material. Microporous Mesoporous Mater 119:165-170

Kavash PA, Seko N, Tamada M, Giiven O (2004) Adsorption efficiency of a new adsorbent towards uranium and vanadium ions at low concentrations. Sep Sci Technol 39(7):1631-1693

Kawai T, Saito K, Sugita K, Katakai A, Seko N, Sugo T, Kanno J, Kawakami T (2000) Comparison of amidoxime adsorbents prepared by co-grafting methacrylic acid and 2-hydroxy ethyl methacrylate with acrylo nitrile onto polyethylene. Ind Eng Chem Res 39:2910-2915

Kulkarni PS (2003) Recovery of uranium(VI) from acidic wastes using tri-n-octylphosphine oxide and sodium carbonate based liquid membranes. Chem Eng J 92:209-214

Ladeira ACQ, Morais CA (2005) Effect of ammonium, carbonate and fluoride concentration on the uranium recovery by resin. Radiochim Acta 93:207-209

Lee W, Lee SE, Kim MK, Lee CH, Kim YS (2002) Chelating resin containing 2-(2-thiazolylazo)-5-dimethylaminophenol as the functional group: synthesis and sorption behaviour for some trace metal ions. Bull Korean Chem Soc 23(8):1067-1072

Lee KH, Muraoka Y, Oshima M, Motomizu S (2004) Determination of heavy metals and rare earths elements in environmental samples by ICP-MS after solid phase pre-concentration with chelating fibres and anion exchange filters. Anal Sci 20(1):183-187

Li J, Qi T, Wang L, Liu C, Zhang Y (2007) Synthesis and characterization of imidazole-functionalized SBA-15 as an adsorbent of hexavalent chromium. Mater Lett 61:3197-3200

Li B, Raff J, Barkleit A, Bernhard G, Foerstendorf H (2010) Complexation of U (VI) with highly phosphorylated protein, phosvitin: a vibrational spectroscopic approach. J Inorg Biochem 104:718-725
Liao X, Lu Z, Du X, Liu X, Shi B (2004) Collagen fiber immobilized Myrica rubra tannin and its adsorption to $\mathrm{UO}_{2}^{2+}$. Environ Sci Technol 38:324-328

Lin C, Wang H, Wang Y, Cheng Z (2010) Selective solid-phase extraction of trace thorium (IV) using surface-grafted Th(IV)imprinted polymers with pyrazole derivative. Talanta 81:30-36

Lloyd JR, Renshaw J, Moanna C (2005) Bioremediation of radioactive waste: radionuclide-microbe interactions in laboratory and field scale studies. Curr Opin Biotech 16:254-260

Mangrulkar PA, Kamble SP, Meshram J, Rayalu SS (2008) Adsorption of phenol and $o$-chlorophenol by mesoporous MCM-41. J Mater 160:414-421

Matsumiya H, Masai H, Terazono Y, Iki N, Miyano S (2003) Chelating adsorbent for heavy metal ions prepared by loading anion exchange resin with thiacalix [4] arenetetrasulfonate. Bull Chem Soc Jpn 76:133-136

Mirjalili K, Roshani M (2007) Resin-in-pulp method for uranium recovery from leached pulp of low grade uranium ore. Hydrometallurgy 85:103-109

Mohite B, Jadhav S, Amol S (2003) Column chromatographic separation of uranium (VI) and other elements using poly dibenzo-18-crown-60 and ascorbic acid medium. J Chromatogr A983:277-281

Nascimentoa MRL, Fatibello-Filhob O, Teixeira LA (2004) Recovery of uranium from acid mine drainage water by ion exchange. Miner Process Extr Metall Rev 25:129-142

Pal S, Tewari PK (2010) Composite sorbent for attrition minimization. Desalination Water Treat 28:1-6

Pal S, Ramchandran V, Prabhakar S, Tewari PK, Sudersanan M (2006) Polyhydroxamic acid sorbents for uranium recovery. J Macromol Sci Part A Pure Appl Chem 43:735-747

Rivas BL, Pooley SA, Maturana HA, Villegas S (2001) Metal ion uptake properties of acrylamide derivative resins. Macromol Chem Phys 202:443-447

Sepehrian H, Samadfam M, Asadi Z (2012) Studies on the recovery of uranium from nuclear industrial effluent using nanoporous silica adsorbent. Int J Environ Sci Technol 9:629-636

Singh SK, Dhami PS, Tripathi SC, Dakshinamurthi A (2009) Studies on the recovery of uranium from phosphoric acid medium using synergistic mixture of (2-ethyl hexyl) phosphoric acid, mono (2ethyl hexyl) ester (PC88A) and tri- $n$-butyl phosphate (TBP). Hydrometallurgy 95:170-174

Sodaye H, Nisan S, Poletiko C, Prabhakar S, Tewari PK (2008) Extraction of uranium from the concentrated brine rejected by integrated nuclear desalination plants. Desalination 235(1-3):9-32

Sprynskyy M, Kovalchuk I, Buszewski B (2010) The separation of uranium ions by natural and modified diatomite from aqueous solution. J Hazard Mater 181:700-707

Starvin AM, Rao TP (2004) Solid phase extractive preconcentration of uranium (VI) onto diarylazobisphenol modified activated carbon. Talanta 63:225-232

Tsuruta T (2002) Removal of uranyl ion using various microorganisms. J Bisosci Bioeng 94:23-28

Van Horn JD, Huang H (2006) Uranium (VI) bio-coordination chemistry from biochemical, solution and protein structural data. Coord Chem 250(7-8):765-775

Wang H, Ma L, Cao K, Geng J, Liu J, Song Q, Yang S, Li S (2012) Selective solid-phase extraction of uranium by salicylideneimine-functionalized hydrothermal carbon. J Hazard Mater 229-230:321-330

Zhang A, Asakura T, Uchiyama G (2003) The adsorption mechanism of uranium (VI) from seawater on a macroporous fibrous polymeric adsorbent containing amidoxime chelating functional group. React Funct Polym 57(1):67-76

Zhang X, Ding C, Liu H, Zhao C (2011) Protective effects of ionimprinted chitooligosaccharides as uranium-specific chelating agents against the cyto-toxicity of depleted uranium in human kidney cells. Toxicology 286:75-84 